\title{
The effect of sintering temperature on crystal structure and microstructure of Pr0.67Ba0.33MnO3 ceramic.
}

\begin{abstract}
Polycrystalline perovskite manganites of $\mathrm{Pr} 0.67 \mathrm{Ba} 0.33 \mathrm{MnO} 3$ bulk ceramic samples were prepared via conventional solid-state reaction. The influence of structure and microstructure towards sintering temperature of the samples were studied. At lower sintering temperature $\left(900^{\circ} \mathrm{C}, 1100^{\circ} \mathrm{C}\right.$ and $\left.1100^{\circ} \mathrm{C}\right)$ other phases such as $\mathrm{PrO} 2$ and $\mathrm{BaMnO} 3$ were detected using XRD and further confirmed with EDX analysis. Furthermore, phase purification and crystal structure transformation was observed in sample sintered at $1200^{\circ} \mathrm{C}$ and $1300^{\circ} \mathrm{C}$ respectively. SEM analysis indicated that higher sintering temperature promotes grain growth and densification. Overall, in this paper, phase purification and crystal structure transformation had been observed. Orthorhombic structure is more favorable to form at higher sintering temperature for Pr0.67Ba0.33MnO3.
\end{abstract}

Keyword: Sintering temperature; Crystal structure transformation; Phase purification. 